\title{
WORKSHOP PEMBUKUAN SEDERHANA KOPERASI PERAJIN BLANGKON MAJU UTAMA SURAKARTA
}

\author{
Bambang Widarno \\ bwidarno@yahoo.com \\ Universitas Slamet Riyadi \\ Hudi Kurniawanto \\ hudi.kurniawanto@gmail.com \\ Universitas Slamet Riyadi
}

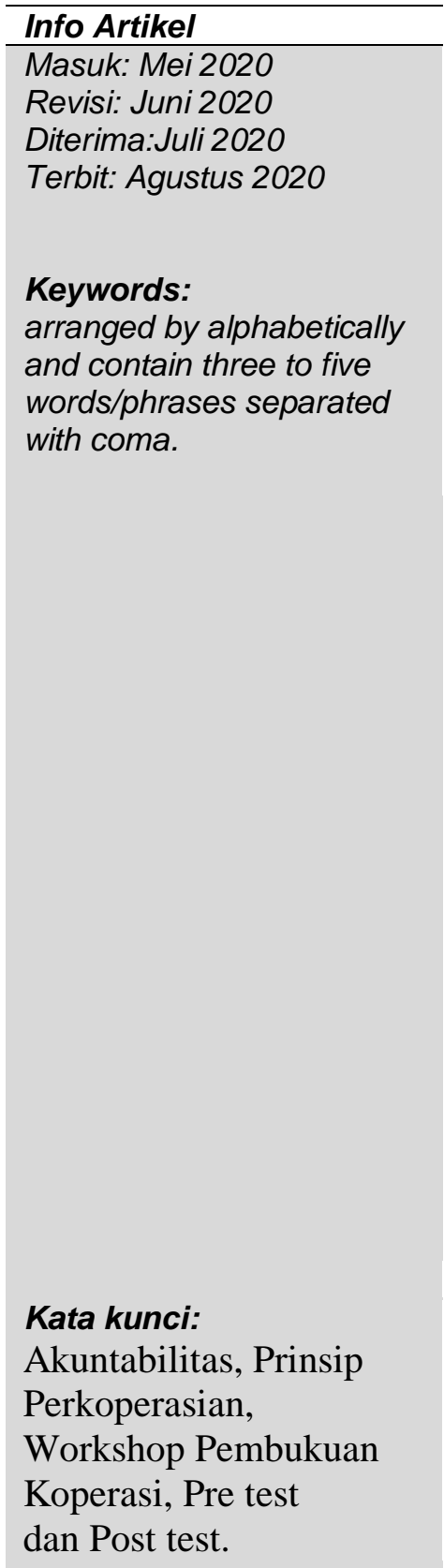

\begin{abstract}
Cooperatives need to implement accountability in an orderly and sustainable manner based on cooperative principles and good bookkeeping in order to gain the trust of the Members. Accountability includes aspects: organization and management, business and services to members, and finance. The socialization and training activities carried out by the Slamet Riyadi University Dedication Team aim to equip Members and Managers of the Maju Utama Cooperative. The number of participants 18 people took place on Saturday, October 5, 2019 at the H. Inoe Mosque Complex, Potrojayan RT $02 \mathrm{RW} 06$ Serengan, Surakarta. The event, which starts at 19.30 - 21.30 West Indonesia Time, was opened by the Chairperson of the Board of Directors, the socialization program with learning methods in the form of lectures, discussions, case studies or Problem Based Learning. Participants were given the questions pretest and posttest as evaluation material. The results of the pretest and posttest showed an increase in scores (scores) from an average of 4.22 to 8.06 so it can be said that from those who previously lacked understanding they understood cooperative. The participants were quite enthusiastic, this can be seen from the number of participants who responded to the explanation of the speakers there were 5 people. The first socialization material by Dr. Hudi Kurniawanto, SE, MM. about the principle of cooperatives, and the second workshop on Bookkeeping Cooperatives by Bambang Widarno, SE., MM.
\end{abstract}

\begin{tabular}{l}
\hline Abstrak \\
\hline Koperasi perlu menerapkan akuntabilitas secara tertib dan \\
berkelanjutan berdasarkan prinsip-prinsip koperasi dan \\
pembukuan yang baik agar mendapat kepercayaan dari \\
Anggota. Akuntabilitas meliputi aspek: organisasi dan \\
manajemen, usaha dan pelayanan kepada anggota, dan \\
keuangan. Kegiatan sosialisasi dan pelatihan yang dilakukan
\end{tabular}


P-ISSN: 2598-2273

E-ISSN: 2598-2281

\section{PENDAHULUAN}

Koperasi mempunyai fungsi dan peran membangun dan mengembangkan potensi dan kemampuan ekonomi anggota pada khususnya dan masyarakat pada umumnya. Koperasi diharapkan mampu menjadi sokoguru memperkokoh perekonomian rakyat sebagai dasar kekuatan dan ketahanan perkonomian nasional. Koperasi sebagai bentuk usaha bersama berdasar atas asas kekeluargaan dan demokrasi ekonomi dalam berusaha harus melaksanakan prinsip koperasi ebagaimana dalam Pasal 5 Undang-Undang No. 25 Tahun 2019 tentang Perkoperasian.

Koperasi sebagai badan usaha perlu menerapkan akuntabilitas dengan tata kelola organisasi, usaha, dan keuangan yang baik agar mendapatkan kepercayaan dari Anggota, masyarakat, dan pemerintah. Anggota harus memiliki pemahaman yang baik tentang prinsip perkoperasian agar timbul kesadaran yang tinggi dalam berkoperasi. Pengurus harus memiliki pengetahuan tentang pembukuan koperasi yang baik agar tercipta administrasi simpan pinjam dan penyusunan laporan keuangan yang baik sebagai bentuk pertanggung-jawaban.

Koperasi Maju Utama baru didirikan pada bulan Oktober 2018 oleh Perajin Blangkon yang berlokasi di Kecamatan Serengan, Surakarta. Kendala yang dihadapi 
Koperasi Maju Utama adalah tentang kesadaran Anggota dalam berkoperasi. Diperlukan perubahan sikap, mental dan pandangan (mindset) Anggota dalam berkoperasi. Beberapa masalah yang mendasar dan turunannya jika diidentifikasi adalah sebagai berikut: 1) minimnya strata pendidikan Anggota menyebabkan sebagian Anggota kurang berfikir rasional, contohnya tidak menyelesaikan kewajiban sebagai Anggota koperasi berupa kewajiban membayar Simpanan Pokok dan Simpanan Wajib, kurang menimbang antara manfaat dan keburukan menjadi Anggota Koperasi, sebagian kurang bertanggung jawab bila diberi amanah. 2) Mental perajin, sebagian masih mengharapkan bantuan dari berbagai pihak, dan tidak memakai bantuan tersebut sebagai modal yang seharusnya dikembangkan, dan 3) manajemen usaha yang masih menyatu dengan rumah tangga, menyulitkan perajin mengetahui perkembangan usaha, bahkan ironisnya kebutuhan rumah tangga dapat mengancam kesinambungan usaha.

Anggota Koperasi memiliki latar belakang pendidikan dan pengetahuan perkoperasian yang relatif rendah. Namun Pengurus yang memiliki semangat tinggi dalam berkoperasi ingin penerapan administrasi Koperasi Maju Utama lebih baik dan mudah diterapkan. Koperasi Maju Utama memiliki potensi dan kesempatan untuk maju. Pemerintah Kota Surakarta yang telah menetapkan wilayah Potrojayan sebagai Sentra Pembuatan Blangkon di Surakarta akan ditingkatkan menjadi Kawasan Tujuan Wisata Blangkon di Surakarta. Pemerintah Kota Surakarta akan merevitalisasi suatu kawasan di Potrojayan yang saat ini berfungsi sebagai makam (kuburan) akan diubah menjadi sentra seni yang multifungsi sebagai tempat pemasaran dan produksi blangkon. Pemerintah Kota Surakarta betul-betul menaruh harapan besar agar perajian blangkon di Surakarta bisa eksis dan berkembang. Kegiatan dilaksanakan pada tanggal 5 Oktober 2019, dengan biaya dari Universitas Slamet Riyadi program Pengabdian kepada Masyarakat tahun 2019.

Latar belakang pendidikan pengelola koperasi yang relatif rendah, mempengaruhi dalam berkoperasi dan penerapan akuntansi koperasi. Perlu adanya penyeragaman dalam penyusunan laporan keuangan sesuai dengan perkembangan standar akuntasi, sehingga laporan yang disajikan lebih mudah dipahami, relevan, andal, wajar, konsisten, dan memiliki daya banding. Rumusan masalah dalam kegiatan PkM ini adalah bagaimana penerapan prinsip-prinsip Koperasi Indonesia 
dan penerapan administrasi simpan pinjam dan pembukuan yang baik dan benar di Koperasi Perajin Blangkon “Maju Utama” Surakarta.

\section{A. Target dan Luaran}

Setelah mengikuti sosialisasi dan workshop akuntansi perkoperasian peserta diharapkan memiliki pengetahuan dan pemahaman yang baik tentang koperasi, sehingga timbul kesadaran yang tinggi serta tahu hak dan kewajibannya dalam berkoperasi. Pengurus dapat menerapkan tata cara administrasi simpan pinjam yang lebih sederhana dan baik, serta dapat menyusum laporan keuangan koperasi sebagai bentuk pertanggungjawaban kepada stakeholders.

Luaran kegiatan pengabdian berupa:

1. Pemahaman prinsip-prinsip perkoperasian

2. Buku administrasi dan kartu-kartu sebagai perangkat usaha simpan pinjam koperasi.

3. Kompetensi dalam penyusunan laporan keuangan koperasi

\section{METODE PELAKSANAAN}

Untuk memecahkan masalah yang dihadapi Anggota dan Pengurus Koperasi Maju Utama dilakukan sebagai berikut:

\begin{tabular}{|c|c|c|}
\hline No & Permasalahan & Metode Pemecahan \\
\hline 1 & $\begin{array}{l}\text { Pemahaman prinsip } \\
\text { perkoperasian yang } \\
\text { rendah }\end{array}$ & $\begin{array}{l}\text { Sosialisasi Undang-Undang No. } 25 / 1992 \\
\text { tentang Perkoperasian, khususnya tentang } \\
\text { prinsip dan jatidiri perkoperasian }\end{array}$ \\
\hline 2 & $\begin{array}{l}\text { Administrasi simpan } \\
\text { pinjam yang rumit dan } \\
\text { belum baku }\end{array}$ & $\begin{array}{l}\text { Pembuatan kartu simpan pinjam dan buku } \\
\text { simpan pinjam yang praktis, serta buku } \\
\text { pembantu lainnya. }\end{array}$ \\
\hline 3 & $\begin{array}{l}\text { Belum mampu menyusun } \\
\text { laporan keuangan } \\
\text { koperasi }\end{array}$ & $\begin{array}{l}\text { a. Sosialisasi tentang kewajiban } \\
\text { pembukuan dan karakteristik kualitatif } \\
\text { laporan keuangan } \\
\text { b. Simulasi (workshop) penyusunan } \\
\text { laporan keuangan koperasi. }\end{array}$ \\
\hline
\end{tabular}

Evaluasi Pelaksanaan 
Evaluasi pelaksanaan dilakukan dengan cara sebagai berikut:

1. Memberikan soal pre test dan post test, dengan kriteria sebagai berikut:
a. Rerata skor $0-39$
: Sangat kurang
b. Rerata skor $40-59$
: Kurang
c. Rerata skor $60-69$
: Cukup Baik
d. Rerata skor $70-79$
: Baik
e. Rerata skor $80-100$
: Sangat baik

Efektivitas kegiatan terbukti jika nilai post test lebih tinggi dari pada nilai pre test.

2. Antusiasme peserta yang diukur dari jumlah pertanyaan yang diajukan peserta, dengan ketentuan sebagai berikut:
a. 1 - 2 pertanyaan
: Sangat kurang antusias
b. 3 - 4 pertanyaan
: Kurang antusias
c. 5 - 6 pertanyaan
: Cukup antusias
d. 7 - 8 pertanyaan
: Antusias
e. Lebih dari 8 pertanyaan
: Sangat antusias

\section{B. Ipteks yang Ditransfer}

Koperasi adalah badan usaha yang beranggotakan orang-seorang atau badan hukum Koperasi dengan melandaskan kegiatannya berdasarkan prinsip Koperasi sekaligus sebagai gerakan ekonomi rakyat yang berdasar atas asas kekeluargaan. Koperasi Indonesia berlandaskan Pancasila dan Undang-undang dasar 1945 serta berdasar atas asas kekeluargaan. Koperasi bertujuan memajukan kesejahteraan anggota pada khususnya dan masyarakat pada umumnya serta ikut membangun tatanan perekonomian Nasional dalam rangka mewujudkan masyarakat yang maju ,adil ,dan makmur berlandaskan Pancasila dan Undang-undang Dasar 1945.

\section{Prinsip Koperasi}

Bab II Pasal 5 Undang-Undang No. 25 Tahun 1992 menyebutkan bahwa Koperasi melaksanakan prinsip Koperasi sebagai berikut:

a. Keanggotaan bersifat sukarela dan terbuka ; 
b. Pengelolaan dilaksanakan secara demokratis ;

c. Pembagian sisa hasil usaha dilakukan secara adil sebanding dengan besarnya jasa usaha masing-masing anggota ;

d. Pemberian balas jasa yang terbatas terhadap modal;

e. Kemandirian.

Dalam mengembangkan Koperasi ,maka Koperasi melaksanakan pula prinsip Koperasi: Pendidikan perkoperasian dan Kerjasama antar Koperasi.

Selain memberikan pemahaman tentang perkoperasian Tim juga mensimulasikan dan melatih Pengurus dan Anggota untuk menerapkan pembukuan koperasi, mulai dari awal transaksi sampai dengan penyusunan laporan keuangan. Kerangka workshop pembukuan perkoperasian adalah sebagai berikut:

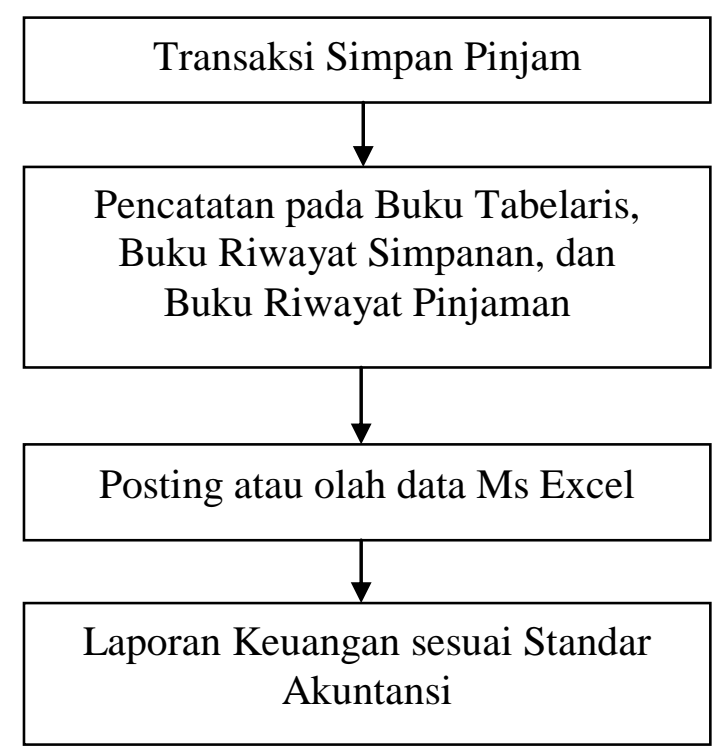

\section{Pembukuan Koperasi}

a. Laporan keuangan

Pengurus Koperasi harus membuat laporan pertanggungjawaban minimal setahun sekali. Laporan keuangan yang harus dibuat ada 2 yaitu

\section{1) Neraca}

Neraca adalah laporan yang menginformasikan tentang harta, utang dan modal koperasi. Persamaannya adalah harta $=$ utang + modal 
Harta atau kekayaan koperasi antara lain berupa: uang kas, piutang (uang yang masih dipinjam anggota), dan inventaris (jika ada). Modal koperasi terdiri dari: simpanan pokok, simpanan wajib, bantuan dari pemerintah, cadangan (bagian dari SHU tahun-tahun sebelumnya), dan SHU periode berjalan.

Jika anggota juga menyimpan simpanan sukarela bisa diambil sewaktu-waktu minimal setahun sekali maka simpanan sukarela tersebut dianggap sebagai utang atau kewajiban koperasi kepada anggota. Namun jika tidak ada simpanan sukarela maka persamaannya adalah harta $=$ modal.

Format neraca adalah sebagai berikut:

Koperasi .....

Neraca

31 Desember 20XX

\begin{tabular}{|c|c|c|c|}
\hline \multicolumn{2}{|l|}{ Harta } & \multicolumn{2}{|c|}{ Kewajiban dan Modal } \\
\hline Uang kas & $X X X$ & Kewajiban & \\
\hline Piutang/pinjaman anggota & $X X X$ & Simpanan Sukarela & $X X X$ \\
\hline Inventaris & $X X X$ & & \\
\hline & & Modal & \\
\hline & & $\begin{array}{l}\text { - } \quad \text { Simpanan pokok } \\
\text { - } \quad \text { Simpanan waiib }\end{array}$ & $\begin{array}{l}X X X \\
X X X\end{array}$ \\
\hline & & - Bantuan pemerintah & $X X X$ \\
\hline & & - Cadangan & $X X X$ \\
\hline & & SHU & $X X X$ \\
\hline Jumlah & $X X X$ & Jumlah & $\mathrm{XXX}$ \\
\hline
\end{tabular}

\section{2) Laporan SHU}

Laporan SHU adalah laporan yang menginformasikan tentang pendapatan, biaya yang dikeluarkan, dan SHU yang diperoleh selama satu periode. Rumusnya adalah pendapatan - biaya $=$ SHU

Pendapatan koperasi adalah dari pembayaran jasa atau bunga pinjaman anggota, denda (jika ada) dan pendapatan administrasi (jika ada). Sedangkan biaya yang dikeluarkan koperasi adalah untuk pembelian buku, biaya administrasi pengurusan hibah, biaya konsumsi, biaya honor/insentif 
pengurus, dan lain-lain, semuanya itu jika ada. Umumnya koperasi masyarakat biaya yang dikeluarkan sangat kecil, honor untuk pengurus biasanya tidak ada, hanya dikeluarkan sekali pada saat RAT (rapat anggota tahunan).

Format laporan SHU adalah sebagai berikut:

Koperasi ....

Laporan SHU

Tahun 20XX

\begin{tabular}{|c|c|c|}
\hline $\begin{array}{l}\text { Pendapatan } \\
\text { - Jasa pinjaman }\end{array}$ & $X X X$ & \\
\hline - Denda (jika ada) & & $X X X$ \\
\hline - $\quad$ Administrasi (jika ada) & $\underline{X X X}$ & \\
\hline Jumlah Pendapatan & & $X X X$ \\
\hline $\begin{array}{l}\text { Biaya } \\
-\quad \text { Biaya administrasi/ATK }\end{array}$ & & $X X X$ \\
\hline - Biaya konsumsi & $X X X$ & \\
\hline - Biaya honor & $X X X$ & \\
\hline - Biaya lain-lain & $\underline{X X X}$ & \\
\hline $\begin{array}{l}\text { Jumlah Biaya } \\
\text { SHU }\end{array}$ & & $X X X$ \\
\hline
\end{tabular}

b. Sistem pembukuan sederhana untuk Koperasi

Pembukuan sederhana adalah dengan sistem baku. Cara ini diyakini yang paling praktis/ simple apalagi karena transaksi tidak bermacam-macam dan jumlah pesertanya relative tetap. Pengurus cukup membuat satu format kosong, kemudian difotocopy. Berikut ini adalah contoh format baku tsb:

\begin{tabular}{|l|l|l|l|l|l|l|}
\hline No & Nama & Ket/HP & $\begin{array}{c}\text { Simpanan } \\
\text { Pokok/Wajib }\end{array}$ & $\begin{array}{c}\text { Angsuran } \\
\text { Pokok }\end{array}$ & Jasa & Pinjaman \\
\hline 1 & A & & & & & \\
\hline 2 & B & & & & & \\
\hline
\end{tabular}




\begin{tabular}{|l|l|l|l|l|l|l|}
\hline 3 & C & & & & & \\
\hline 4 & D & & & & & \\
\hline$\ldots$ & $\ldots$ & & & & & \\
\hline Jumlah & & & & & \\
\hline
\end{tabular}

Teknisnya pengurus tidak perlu menuliskan transaksinya (seperti dalam buku kas) tapi tinggal menuliskan jumlah rupiahnya, sehingga pengurus tidak terlalu repot. Pengurus dapat segera menghitung berapa jumlah uang masuk dari pembayaran simpanan wajib, angsuran pokok dan jasa pinjaman, serta berapa uang yang keluar untuk dipinjamkan kepada anggota.

Format laporan yang harus dibacakan pengurus adalah sbb:

Saldo awal bulan $\mathrm{t}-1$......

$X X X$

Pemasukan:

- Simpanan wajib

$X X X$

- Angsuran pokok

$\mathrm{XXX}$

- Jasa

$\underline{X X X}$

Jumlah Pemasukan

$X X X$

Pengeluaran

- Pinjaman anggota

$\mathrm{XXX}$

- Biaya (jika ada)

$\underline{X X X}$

Jumlah Pengeluaran

Saldo akhir kas bulan $\mathrm{t}$

$\frac{X X X}{X X X}$

Buku lain yang harus dibuat oleh pengurus adalah buku simpanan dan buku pinjaman. Buku ini hanya dipegang oleh pengurus untuk mencatat dan mengetahui riwayat pembayaran simpanan dan pinjaman/angsuran dari anggota. Jika memungkinkan masing-masing anggota dapat dibuatkan kartu simpanan dan kartu pinjaman, agar anggota juga mengetahui berapa saldo atau posisi terakhir simpanan dan pinjamannya di koperasi.

Khusus untuk pengurus harus membuat rekapitulasi buku/kartu simpanan dan buku/kartu pinjaman, untuk selanjutnya total setiap jenis simpanan dan total pinjaman anggota dipindahkan ke dalam laporan keuangan sebagaimana format di atas (lihat bentuk neraca dan laporan SHU) 
a. Buku/kartu simpanan

Buku/Kartu Simpanan Anggota

Nama / NPA :

\begin{tabular}{|c|c|c|c|c|c|}
\hline \multirow{2}{*}{ Tgl } & $\begin{array}{c}\text { Simpanan } \\
\text { Pokok }\end{array}$ & $\begin{array}{c}\text { Simpanan } \\
\text { Wajib }\end{array}$ & & \multicolumn{3}{|c|}{ Simpanan Sukarela } \\
\cline { 4 - 6 } & & & & & Setor \\
& & & & & \\
\hline
\end{tabular}

Rekap kartu simpanan (dibuat dan dipegang pengurus)

\begin{tabular}{|l|l|l|l|l|l|l|}
\hline No & \multicolumn{1}{|c|}{$\begin{array}{c}\text { Nama } \\
\text { Anggota }\end{array}$} & Ket & $\begin{array}{c}\text { Simpanan } \\
\text { Pokok }\end{array}$ & $\begin{array}{c}\text { Simpanan } \\
\text { Wajib }\end{array}$ & $\begin{array}{c}\text { Simpanan } \\
\text { Sukarela }\end{array}$ & Total \\
\hline 1 & A & & & & & \\
\hline 2 & B & & & & & \\
\hline 3 & C & & & & & \\
\hline$\ldots$ & $\ldots$ & & & & \\
\hline \multicolumn{2}{|l|}{ Jumlah (= di neraca) } & & & & \\
\hline
\end{tabular}

b. Buku pinjaman

Buku/Kartu Pinjaman Anggota

Nama / NPA :

\begin{tabular}{|c|c|c|c|c|}
\hline Tgl & Pinjaman & $\begin{array}{c}\text { Angsuran } \\
\text { Pokok }\end{array}$ & Jasa & Saldo \\
\hline & & & & \\
\hline
\end{tabular}

Rekap kartu simpanan (dibuat dan dipegang pengurus)

\begin{tabular}{|l|l|l|l|l|}
\hline No & \multicolumn{1}{|c|}{ Nama Anggota } & Ket & Sisa Pinjaman & $\begin{array}{l}\text { Jasa yg } \\
\text { Dibayar }\end{array}$ \\
\hline 1 & A & & & \\
\hline 2 & B & & & \\
\hline 3 & C & & & \\
\hline$\ldots$ & $\ldots$ & & \\
\hline Jumlah (= di neraca) & & & \\
\hline
\end{tabular}


Hasil yang dicapai dari kegiatan PkM adalah:

1. Adanya peningkatan pemahaman Anggota tentang perkoperasi, sebagaimana hasil pre test dan post test

\begin{tabular}{|c|l|c|c|}
\hline No & \multicolumn{1}{|c|}{ Nama } & $\begin{array}{c}\text { Nilai } \\
\text { Pre test }\end{array}$ & $\begin{array}{c}\text { Nilai } \\
\text { Post test }\end{array}$ \\
\hline 1 & Iwan Haryono & 5 & 8 \\
\hline 2 & Sumarno & 4 & 8 \\
\hline 3 & Ananta Karyana & 5 & 9 \\
\hline 4 & Al Indayatie & 4 & 8 \\
\hline 5 & Yanto & 5 & 9 \\
\hline 6 & Anggoro Widiyanto & 5 & 8 \\
\hline 7 & Kenyot & 6 & 9 \\
\hline 8 & Dwi & 3 & 7 \\
\hline 9 & Sanyoto & 4 & 8 \\
\hline 10 & Saifudin & 3 & 8 \\
\hline 11 & Anggito & 5 & 7 \\
\hline 12 & Ponidi & 3 & 7 \\
\hline 13 & Djoko Surtisno & 7 & 10 \\
\hline 14 & Hery Subagyo & 3 & 7 \\
\hline 15 & Trisiwi & 3 & 7 \\
\hline 16 & Mujiono & 4 & 9 \\
\hline 17 & Anis & $\mathbf{4 . 2 2}$ & $\mathbf{8 . 0 6}$ \\
\hline 18 & Darsono & & \\
\hline \multicolumn{2}{|c|}{ Skor Rata-rata } & & 9 \\
\hline
\end{tabular}

2. Setelah dilakukan simulasi pembukuan juga dilakukan penyerahan dokumen siap pakai kepada Pengurus Koperasi Maju Utama berupa: Kartu Simpanan dan Pinjaman berlaku 1 tahun untuk 35 Anggota, Buku Transaksi berlaku selama 4 tahun, dan Buku Riwayat Pinjaman dan Simpanan Anggota serta contoh laporan keuangan koperasi.

\section{PENUTUP}

1. Acara sosialisasi yang dihadiri oleh 18 orang Anggota selain untuk mensosialisasikan tentang prinsip dan manajemen koperasi, juga bertujuan untuk memotivasi Anggota agar semangat/ giat dalam berkoperasi.

2. Evaluasi pelaksanaan PkM yaitu terdapat peningkatan pemahaman Anggota Koperasi antara sebelum dan sesudah mendapat sosialisasi prinsip 
perkoperasian dan workshop pembukuan koperasi. Hasil pre test menunjukkan perbedaan signifikan dengan hasil post test yaitu dari skor 4,22 menjadi menjadi 8,06. Peserta yang merespon juga cukup antusias yaitu sebanyak 5 orang dari 18 orang peserta yang hadir.

\section{Saran}

1. Perlu sinergi antara pemerintah, akademisi, dan pelaku usaha untuk mewujudkan peningkatan kualitas atau kompetensi pengelola koperasi dan Anggotanya, serta peningkatan kinerja usaha Anggota.

2. Perlu adanya strategi untuk menggerakkan Anggota agar mau mengikuti kegiatan peningkatan kesadaran berkoperasi, misalnya dengan penggabungan antara program penyaluran dana atau pembiayaan murah, hibah, dengan sosialisasi/ pendidkan perkoperasian.

3. Perlu mendatangkan narasumber atau praktisi yang telah sukses menjalankan usaha bersama dengan membentuk wadah koperasi, sehingga Anggota betulbetul meyakini bahwa dengan berkoperasi itu usaha mereka akan berkembang.

4. Perlu ada pemantauan perkembangan atau pendampingan usaha Koperasi oleh Tim PkM secara periodik misalnya setiap triwulan sekali mengecek administrasi perkoperasian sekaligus menyusun laporan keuangan sampai dengan pengurus bisa melakukan penyusunan laporan keuangan secara mandiri.

5. Perlu ada pihak yang menginisiasi atau memberikan informasi tentang akses transfer teknologi dalam rangka peningkatan volume usaha, misalnya tentang teknologi, pemasaran, desain, dan inovasi.

6. Terus mengusulkan kepada Pemerintah untuk mendapat dukungan dan fasilitas permodalan yang ringan, untuk program peningkatan kapasitas usaha, misalnya untuk mengangkat karyawan atau investasi menambah sarana prasarana usaha. 


\section{DAFTAR PUSTAKA}

Achmad H. Gopar, 2009, "Kajian Dampak, Koperasi Terhadap Anggotanya", Jurnal Pengkajian Koperasi dan UKM, Volume 4 tahun 2009, Jakarta.

Dewan Standar Akuntansi Keuangan, 2013, Standar Akuntansi Keuangan, Entitas Tanpa Akuntabilitas Publik, Ikatan Akuntan Indonesia, Jakarta

Ibnoe Soedjono, 2004, Manajemen Profesional Berdasarkan Nilai-nilai Dalam Koperasi, Jakarta: LSP2I.

International Co-operative Alliance, 2009, Jatidiri Koperasi: ICA Co-operative Identity Statement Prinsip-Prinsio Koperasi untuk Abad Ke-21, Terjemahan-Pengantar Ibnoe Soedjono, Jakarta: LSP2I.

Governmental Accounting Standards Board (GASB), 1999, Concepts Statement No. 1 tentang Objectives of Financial Reporting

Gilbert, N. and H. Specht, 1977, Planning for Social Welfare; Issues, Model, and Tasks. New Jersey: Pretice-Hall, Inc.

Jochen Ropke, 2003, Ekonomi Koperasi: Teori dan Manajemen, Edisi Revisi, Terjemahan Sri Djatnika, Jakarta: Salemba Empat.

Mardiasmo, 2006, "Perwujudan Transparansi dan Akuntabilitas Publik Melalui Akuntansi Sektor Publik: Suatu Sarana Good Governance", Jurnal Akuntansi Pemerintah, Vol. 2, No. 1, Mei 2006, Hal 1 - 17

Peraturan Menteri Koperasi Dan Usaha Kecil Dan Menengah Republik Indonesia Nomor 13/Per/M.KUKM/IX/2015 Tentang Pedoman Akuntansi Usaha Simpan Pinjam Oleh Koperasi

Peraturan Menteri Koperasi Dan Usaha Kecil Dan Menengah Republik Indonesia Nomor 20/Per/M.KUKM/IX/2015 Tentang Penerapan Akuntabilitas Koperasi

Ruppel, W. 2007. Not-for-profit Accounting Made Easy. Hoboken, New Jersey: John Wiley \& Sons, Inc.

Suwandi, 2005. Revitalisasi Koperasi Sekunder Nasional. Jurnal Pengkajian Koperasi UKM, No: 26 Tahun XX 2005, Jakarta.

Togap Tambunan dan Jannes Situmorang, 2009, "Kajian Tentang Keterkaitan Koperasi Sekunder dengan Koperasi Primer Anggotanya" Jurnal Pengkajian Koperasi dan UKM, Volume 4 tahun 2009, Jakarta

Undang-Undang Republik Indonesia Nomor 25 Tahun 1992 tentang Perkoperasian (Lembaran Negara Republik Indonesia Tahun 1992 Nomor 116, Tambahan Lembaran Negara Republik Indonesia Nomor 3502). 